\title{
Telhado verde: uma alternativa sustentável para a gestão das águas pluviais
}

\author{
Green roof: a sustainable alternative for stormwater \\ management
}

\section{Rutinéia Tassi \\ Lucas Camargo da Silva Tassinari \\ Daniel Gustavo Allasia Piccilli Cristiano Gabriel Persch}

\section{Resumo}

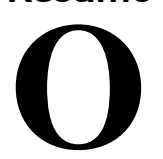

crescimento da população urbana tem gerado impactos negativos muito mais significativos sobre o meio ambiente, tais como as enchentes, que se mostram cada vez mais severas em decorrência da impermeabilização do solo com a falta de um plano de manejo das águas pluviais, e o emprego excessivo de canalizações. Diante da necessidade de uma mudança de paradigma na concepção das obras de drenagem pluvial, surgiu o conceito de Desenvolvimento de Baixo Impacto (DBI), cujo princípio é a gestão das águas pluviais próximo a sua origem, buscando a utilização de técnicas que permitam mimetizar funções naturais que são perdidas com a urbanização. Nesse contexto, os telhados verdes vêm sendo empregados, pois, além de outros benefícios, contribuem para o controle quali-quantitativo das águas pluviais. Neste trabalho são apresentados os resultados de um estudo de longo prazo sobre a eficiência de um telhado verde no controle quantitativo das águas pluviais. Foi possível reduzir, em média, $62 \%$ do escoamento superficial, promovendo um retardo no escoamento e reduzindo as vazões de pico, o que gerou o controle desejado. No entanto, sua eficiência é altamente influenciada pelas condições climáticas e de umidade do solo que antecedem cada evento chuvoso.

Rutinéia Tassi Universidade Federal de Santa Maria Santa Maria - RS - Brasil

Lucas Camargo da Silva Tassinari Universidade Federal de Santa Maria Santa Maria - RS - Brasil

Daniel Gustavo Allasia Piccilli Universidade Federal de Santa Maria Santa Maria - RS - Brasil

Cristiano Gabriel Persch Engenheiro Civil Santa Maria - RS - Brasil

Recebido em 15/04/13 Aceito em 30/09/13
Palavras-chave: Telhado verde. Controle. Escoamento pluvial. Desenvolvimento Urbano de Baixo Impacto.

\section{Abstract}

Negative impacts on the environment, such as floods severity, have been significantly intensified due to urban population growth, soil imperviousness, the lack of a Stormwater Management Plan, and the overuse of channelization.

Therefore, the need of a paradigm shift in the traditional conception of stormwater drainage originated the concept of Low Impact Development (LID), which has as a principle to manage stormwater as close to its source as possible by applying techniques that allow restoring natural functions lost due to urbanization process. In this context, the use of green roofs is a widely accepted technique because of its contribution to the quali-quantitative stormwater control, besides other benefits. This paper presents the results of a long-term study about the efficiency of a green roof on the quantitative stormwater control. It was possible to reduce, on average, $62 \%$ of runoff, promoting a runoff delay and a reduction on peak flow, allowing, therefore, the desired control. However, its efficiency is highly dependent on climatic and precedent soil moisture conditions.

Keywords: Bamboo. Green roof. Control. Stormwater. Low Impact Development.

TASSI, R.; TASSINARI, L. C. da S.; PICCILLI, D. G. A.; PERSCH, C. G. Telhado verde: uma alternativa sustentável para a 139 gestão das águas pluviais. Ambiente Construído, Porto Alegre, v. 14, n. 1, p. 139-154, jan./mar. 2014.

ISSN 1678-8621 Associação Nacional de Tecnologia do Ambiente Construído. 


\section{Introdução}

Segundo dados do Fundo de População das Nações Unidas (UNITED..., 2013), a população mundial já ultrapassa 7 bilhões de pessoas. No Brasil, a população já é superior a 190 milhões de indivíduos (IBGE, 2010), tendo aumentado o grau de urbanização de aproximadamente $81 \%$, em 2000, para mais de $84 \%$, em 2010.

Com o crescimento urbano, as edificações e obras de infraestrutura urbana (ruas, passeios públicos, estacionamentos, telhados, etc.) alteram significativamente a cobertura do solo e a topografia. Além dos impactos diretos aos ecossistemas terrestres e aquáticos, o clima urbano é modificado.

Ocorre a formação do efeito conhecido como ilha de calor urbano como resultado da substituição de áreas verdes por superfícies compostas de concreto e asfalto. Essas superfícies absorvem e retêm calor por mais tempo que as áreas verdes (ROCHA; SOUZA; CASTILHO, 2011), resultando em um acréscimo da temperatura na cidade e, consequentemente, no aumento dos custos de refrigeração dos ambientes (GIBBS et al., 2006).

A introdução de superfícies impermeáveis no espaço urbano também reduz a possibilidade de infiltração das águas pluviais e as taxas de evapotranspiração, os caminhos naturais de escoamento são eliminados, e há um aumento nas vazões e no volume das águas pluviais que são escoadas superficialmente. Nota-se, ainda, o aumento da pluviosidade urbana no verão, o que contribui para o aumento do problema das enchentes e a desumidificação causada, sobretudo, pela diminuição da evapotranspiração devido à ausência de vegetação (PINTO, 2007). A alteração dos processos hidrológicos no meio urbano provoca o aumento do escoamento superficial da situação de pré-ocupação em várias ordens de grandeza (UNITED..., 2003; URBONAS; STAHRE, 1993; TUCCI, 2005; CLARKE; KING, 2005), traduzindo-se em enchentes.

Nos últimos anos, as enchentes têm-se tornado mais graves e frequentes, demonstrando a fragilidade do sistema hidrológico urbano no qual pequenas mudanças podem acarretar grandes alterações em seu funcionamento, com significativos impactos financeiros e psicológicos sobre a população (BRAGA; CARVALHO, 2003).

Tradicionalmente, o tratamento dado ao escoamento superficial no meio urbano tem sido o de introdução de sistemas de drenagem eficientes em sua captação e afastamento, minimizando os danos provocados pelas inundações. Essa abordagem, no entanto, acaba apenas transferindo os impactos do aumento do escoamento superficial para regiões que se encontram a jusante, e é insustentável, pois, à medida que a impermeabilidade aumenta, novas obras, ou mesmo ampliações, são necessárias. Além disso, frequentemente, o escoamento superficial é conduzido diretamente a um corpo hídrico receptor, ignorando a passagem por áreas com potencial de infiltração e conexão com planícies de inundação, que são altamente eficientes na remoção de poluentes (KAUSHAL et al., 2008).

Algumas estratégias podem ser aplicadas para mitigar os impactos negativos da impermeabilização das superfícies nas áreas urbanas. O mais comum é tratar os sintomas da impermeabilidade superficial mediante o emprego de práticas da engenharia, com o uso de estruturas conhecidas internacionalmente como BMP - Best Management Practices (Melhores Práticas de Gestão). Essas estruturas são projetadas e construídas para reter o volume escoado superficialmente e promover a melhoria da qualidade da água, normalmente com o emprego de processos biológicos.

Entre as estruturas utilizadas para esses fins podem ser citadas as bacias de retenção, banhados construídos, áreas de biorretenção, filtros de areia, entre outros (UNITED..., 2003). Uma segunda estratégia consiste na identificação de áreas com elevado valor ecológico na paisagem e sua proteção, de maneira a evitar sua conversão em área impermeável. Isso normalmente é realizado mediante a criação de parques ou corredores ecológicos, com a utilização de instrumentos legais (ARENDT, 2004). Frequentemente as zonas ripárias são identificadas e incorporadas ao espaço verde a ser preservado na área urbana, de maneira a garantir que se manterá inalterado, mediante fiscalização.

Outra medida igualmente possível em áreas em que o desenvolvimento urbano ainda não está consolidado é a utilização de técnicas conhecidas como LID - Low Impact Development (Desenvolvimento de Baixo Impacto - DBI). Entre os princípios do DBI, pode ser citada a introdução de técnicas alternativas para o controle do escoamento pluvial junto à fonte onde é gerado, buscando a minimização (ou mesmo a eliminação) dos volumes e vazões que escoam superficialmente a valores próximos àqueles que ocorriam no estágio anterior à impermeabilização do solo (impacto zero devido à urbanização). Além disso, essas técnicas devem estar inseridas na paisagem natural, promovendo o menor impacto visual, e utilizar as próprias funções da natureza para 
promover o manejo das águas pluviais (UNITED..., 2003). Sua aplicação em ampla escala ajuda a manter as funções ecológicas e hidrológicas na bacia hidrográfica, sendo caracterizada pela Water Environment Research Foundation como uma prática sustentável voltada para a drenagem pluvial (CLARK et al., 2006). Entre as técnicas normalmente empregadas neste sentido, podem ser citadas as pequenas biorretenções, paisagismo com água da chuva, aproveitamento de água da chuva, trincheiras de infiltração, pavimentos permeáveis e telhados verdes, entre outros.

Especificamente com relação aos telhados verdes, alguns estudos demonstram que essa prática confere, simultaneamente, múltiplos benefícios, como uma significativa melhora da qualidade ambiental, atuando como inibidor das zonas de calor (ROSENZWEIG; GAFFIN; PARSHALL, 2006), sequestrador de poluentes (YANG; YU; GONG, 2008) e aumentando a biodiversidade e habitats perdidos em áreas urbanizadas (KIM, 2004); tanto a vegetação como o substrato de solo atuam sobre o controle do escoamento pluvial superficial, através dos processos de interceptação, armazenamento de água no solo e evapotranspiração (YANG; YU; GONG, 2008), mitigando os impactos da impermeabilização dele.

O telhado verde também confere melhorias quanto ao conforto térmico (VECCHIA, 2005; BEYER, 2007) e acústico (RENTERGHEM; BOTTELDOOREN, 2009), já que a vegetação e o solo atenuam tanto a transmissão de calor como de ruído para o interior da edificação, o que gera, também, economia de energia (GIBBS et al., 2006). A possibilidade de acessibilidade, o apelo estético para os ocupantes da edificação e o potencial para a agricultura urbana são igualmente benefícios proporcionados pelo uso de coberturas verdes (PECK et al., 1999).

Telhados verdes apresentam ainda potencial de proteger a cobertura contra a ação dos raios ultravioletas, extremos de temperatura, efeitos do vento no telhado e contração e retração estrutural, o que aumenta a vida útil das estruturas do telhado. Sua implementação também permite a obtenção de créditos no programa LEED (Leadership in Energy and Environmental Design), administrado pelo U.S. Green Building Council, uma agência que promove a elaboração de projetos e a construção de edificações que possuem responsabilidade ambiental, lucratividade e ambientes saudáveis para se viver e trabalhar (UNITED..., 2005). Este programa traz incentivos econômicos e financeiros para o mercado das construções verdes nos Estados Unidos, onde a certificação é concedida pelo USGBC (United
States Green Building Council) desde 1999. No Brasil, a avaliação e certificação LEED para construções sustentáveis é concedida pelo Green Building Council Brasil, criado em 2007. Embora ainda não existam incentivos econômicos no Brasil, muitos empreendimentos estão sendo construídos dentro dos critérios necessários para a obtenção de tal certificação, que incluem uso racional da água, energia eficiente, entre outros, em razão de um menor consumo energético durante a vida útil da obra, e a obtenção de benefícios financeiros indiretos, a exemplo do marketing.

Destaca-se, no entanto, que a maioria dos relatos afirmando a eficiência dos telhados verdes no controle do escoamento pluvial é proveniente de outros países, com condições climáticas diferenciadas da brasileira. Aqui, os estudos realizados com telhados verdes nesse sentido são relativamente recentes. Alguns autores, a exemplo de Costa, Costa e Poleto. (2012) e Santos et al. (2013), realizaram simulações experimentais com chuvas sintéticas para avaliar a eficiência de telhados verdes no controle quantitativo do escoamento pluvial. Outros autores, como Mendiondo e Cunha (2004), Castro e Goldenfum (2010) e Baldessar (2012), apresentam resultados a respeito da eficiência de telhados verdes sob condições de chuvas reais, no entanto durante um curto período de monitoramento, da ordem um a três meses.

Assim, este artigo pretende avançar nesse sentido, apresentando os resultados de uma pesquisa que incluiu monitoramento e modelagem de um telhado verde, e objetivou avaliar a sua eficiência no controle quantitativo do escoamento pluvial, no longo prazo. Além de focar aspectos relacionados com a redução nas vazões e volumes escoados, o artigo também mostra como os resultados obtidos foram influenciados pelas condições climáticas e condições de chuvas antecedentes.

\section{Telhados verdes}

Os telhados verdes são conhecidos por converter a superfície de um telhado convencional em um espaço multifuncional, utilizando, para isso, a vegetação. Essa prática tem sido utilizada extensamente na Alemanha por mais de 30 anos. Em 2002, mais de $12 \%$ dos telhados planos daquele país possuíam algum tipo de vegetação (HARZMANN, $2002^{1}$ apud CARTER; BUTLER, 2008).

\footnotetext{
${ }^{1}$ HARZMANN, U. German Green Roofs. In: ANNUAL GREEN ROOF CONSTRUCTION CONFERENCE, Chicago, 2002. Proceedings... Chicago, 2002.
} 
De acordo com Hydrotec Membrane Corporation (2007), os telhados verdes podem ser concebidos com diferentes conceitos, com relação ao tipo de uso previsto e de vegetação que vai comportar. Costuma-se separar os diferentes tipos de telhados verdes em duas grandes categorias: os sistemas extensivos e sistemas intensivos.

Os sistemas extensivos são coberturas leves, projetadas para comportar plantas resistentes a situações climáticas severas. Apresentam bom comportamento diante da redução de escoamento superficial de água (YANG; YU; GONG, 2008), à redução dos efeitos das ilhas de calor urbanas (ROSENZWEIG; GAFFIN; PARSHALL, 2006) e ao aumento da umidade no ambiente (PINTO, 2007). Em termos físicos, possui pouca profundidade de solo $(5 \mathrm{~cm}$ a $15 \mathrm{~cm})$, adicionando pouco peso à estrutura que o suporta. Contudo, as plantas devem ser resistentes a diferentes eventos climatológicos, como seca, geada e ventos fortes. Normalmente, a água é armazenada no substrato, e a drenagem, ou camada de retenção, é suficiente para sustentar a necessidade hídrica das plantas; no entanto, um sistema de irrigação pode ser empregado para garantir a sobrevivência da vegetação durante períodos prolongados de estiagem. Com a aplicação de vegetação adequada, os sistemas de irrigação normalmente não se fazem necessários, exceto em climas extremos.

Nos telhados verdes intensivos, a profundidade do solo é mais significativa $(15 \mathrm{~cm}$ a $90 \mathrm{~cm})$, o que permite a utilização de plantas de maior porte que aquelas utilizadas no sistema extensivo, podendo ser empregados arbustos e até mesmo árvores. Dependendo da concepção utilizada, podem destinar-se a fins desportivos, recreativos e de lazer, e, muitas vezes, são indistinguíveis de jardins naturais em sua aparência. Seguem o mesmo conceito de projeto de um telhado extensivo, contudo a camada de drenagem ou retenção é, geralmente, mais profunda. Os telhados intensivos geralmente necessitam de um sistema de irrigação, e a água retida na drenagem pode ser usada para irrigar as plantas cultivadas.

De maneira geral, um telhado verde apresenta a seguinte estrutura (Figura 1):

(a) camada de vegetação: a cobertura vegetal deve ser adequada às condições climáticas do local. A vegetação atua interceptando uma parcela da chuva, evitando que ela atinja o solo. É por meio do processo de evapotranspiração que a água é perdida para a atmosfera e o potencial de retenção de água no substrato é aumentado. Adicionalmente, a vegetação retarda o escoamento superficial, que passa a ocorrer quando o substrato atinge a saturação; (b) substrato: é constituído pela camada de solo, servindo de suporte para a fixação da vegetação, fornece água e nutrientes necessários para a manutenção desta. Essa camada é igualmente importante para o armazenamento temporário da água durante os eventos chuvosos;

(c) geotêxtil: constitui uma camada filtrante que separa as camadas de vegetais e substrato da camada drenante. Ela evita a migração de partículas do substrato para o interior da camada drenante, reduzindo a funcionalidade do telhado verde;

(d) camada de drenagem: em telhados praticamente horizontais, como é o caso dos telhados verdes, é fundamental a existência da camada de drenagem, para evitar alagamentos indesejáveis e estresse da cultura. Além disso, a camada de drenagem atua retendo parte da água da chuva, necessária para a vegetação durante períodos de estiagem;

(e) camada protetora: destina-se à retenção da umidade e nutrientes acima da estrutura do telhado, fornecendo proteção física para a membrana de impermeabilização contra o crescimento das raízes da vegetação;

(f) impermeabilização: normalmente realizada com o emprego de hidrorrepelentes, de maneira a evitar o contato da água com a estrutura do telhado; e

(g) estrutura do telhado: deve suportar toda a carga do telhado verde. Para o sistema extensivo com substrato de $5 \mathrm{~cm}$ a $15 \mathrm{~cm}$ de espessura, estima-se que a carga sobre o telhado possa aumentar de 70 a $170 \mathrm{~kg} / \mathrm{m}^{2}$ aproximadamente. Para o sistema intensivo, com espessura de solo acima de $15 \mathrm{~cm}$, o valor de carga adicional pode variar entre 290 e $970 \mathrm{~kg} / \mathrm{m}^{2}$ (HENEINE, 2008).

Evidentemente, a espessura da camada do substrato e altas taxas de evapotranspiração podem beneficiar a retenção de água pluvial no telhado verde, pois o substrato armazena água, mas os processos de evapotranspiração promovem o esvaziamento dele, aumentando a eficiência do telhado no armazenamento do escoamento pluvial.

Portanto, os telhados intensivos seriam indicados como melhor alternativa para o controle quantitativo do escoamento pluvial. No entanto, isso não é praticável na maioria dos casos, devido à sobrecarga exercida; além disso, não podem ser empregados em telhados inclinados e requerem uma manutenção comparável àquela empregada em jardins. 
Figura 1 - Camadas que compõem o telhado verde

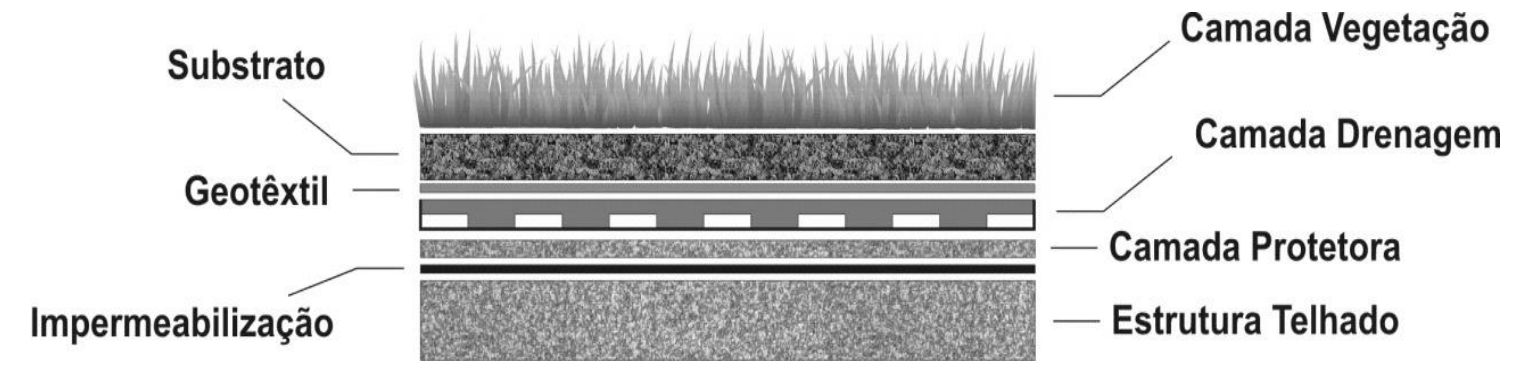

A eficiência quanto ao controle quantitativo do escoamento pluvial pode ser verificada a partir do cálculo do coeficiente de escoamento (C), que traduz o percentual do volume de chuva que é convertido em escoamento superficial. Assim, baixos valores de $\mathrm{C}$ indicam elevada eficiência do telhado verde na armazenagem de água da chuva, e valores mais elevados normalmente estão associados a maiores volumes de chuva (OLIVEIRA, 2009). Alguns estudos também mostram que o valor do coeficiente de escoamento pode variar em função da inclinação do telhado verde, da espessura da camada de substrato e do tipo de vegetação, além da quantidade de água acumulada em sua estrutura no período que antecede o evento chuvoso, conhecida como umidade antecedente do solo (UAS) (Tabela 1, onde os coeficientes foram estimados em eventos de $300 \mathrm{~L} / \mathrm{s}$.ha e telhados previamente secos por 24 h).

No Brasil, Santos et al. (2013) simularam a dinâmica da água em dois telhados verdes com vegetações distintas para diferentes intensidades de precipitação na região de Pernambuco e verificaram uma redução no escoamento superficial entre $15 \%$ e $30 \%$ do total precipitado. Baldessar (2012), em um monitoramento de telhado verde na cidade de Curitiba, PR, verificou uma redução no escoamento pluvial da ordem de $31 \%$. Mediondo e Cunha (2004) não apresentam valores para a redução no escoamento pluvial de um telhado verde experimental na cidade de São Carlos, SP, mas destacam que foi possível armazenar cerca de $14 \mathrm{~mm} / \mathrm{m}^{2}$ de água quando o solo está seco.

\section{Materiais e métodos}

$\mathrm{O}$ presente trabalho avaliou como um telhado verde contribui para o controle quantitativo do escoamento pluvial. Para isso, durante 17 meses foi realizado o monitoramento de um modelo experimental, com o objetivo de avaliar seu efeito sobre o escoamento pluvial, por meio da determinação do coeficiente de escoamento superficial, determinação do volume máximo de armazenamento do telhado e retardo na geração de escoamento ante os diferentes eventos de precipitação.

Além do monitoramento de eventos isolados, os resultados obtidos durante o período de monitoramento foram utilizados para a calibração de um modelo de balanço de volumes, que foi utilizado para a realização de um prognóstico de longo período sobre o comportamento esperado do telhado verde. Um detalhamento sobre o protótipo construído e monitorado bem como os procedimentos empregados para as análises são descritos a seguir.

\section{Materiais}

Junto às dependências da Universidade Federal de Santa Maria, RS, foi construída uma estrutura de telhado com aproximadamente $12 \mathrm{~m}^{2}$, dividida em duas regiões, metade da área com cobertura verde (telhado verde) e a outra metade com telhado convencional com cobertura de telha de fibrocimento (Figura 2), sendo a declividade de ambos os telhados de $1 \%$. A porção com telhado convencional foi utilizada para a obtenção de dados de referência, utilizados para avaliar, comparativamente, o comportamento do telhado verde. O telhado foi construído em outubro de 2010, e seu monitoramento realizado até o mês de julho de 2012.

O sistema do telhado verde empregado é extensivo, composto de módulos pré-fabricados. Os módulos possuem uma estrutura na forma de caixa, com um composto de EVA reciclado moído e aglomerado com cimento Portland CP-V com adição de cinzas. $\mathrm{O}$ módulo tem dimensões de $70 \times 35 \times 9 \mathrm{~cm}$ (comprimento x largura x altura), com oito células, dentro das quais é colocado o substrato de terra e é inserida a vegetação. Essa estrutura é assentada sobre um recipiente plástico (galocha), que tem aproximadamente $3 \mathrm{~cm}$ de altura e a função de reter uma parcela da água da chuva, que é utilizada pela vegetação durante os períodos de estiagem. O modelo de telhas utilizado na estrutura do telhado verde é apresentado na Figura 3 e foi obtido por meio de doação de uma 
empresa da cidade de Porto Alegre, RS, cujo foco é o desenvolvimento de produtos voltados para a infraestrutura verde urbana no Brasil. Na área reservada ao telhado verde foram instalados 24 módulos, cada qual com oito células, preenchidas por terra (aproximadamente $8 \mathrm{~cm}$ ) e vegetação. $\mathrm{O}$ telhado convencional foi revestido com telhas de fibrocimento, totalizando uma área igual àquela do telhado verde. A Figura 4 mostra uma fotografia da vista superior do telhado verde implantado no experimento, onde é possível visualizar os módulos e a vegetação utilizada no experimento.

Tabela 1 - Variação do coeficiente de escoamento em relação à espessura do substrato e inclinação do telhado

\begin{tabular}{lcc}
\hline \multicolumn{1}{c}{ Espessura $(\mathbf{c m})$} & Inclinação até $\mathbf{~ 1 5}^{\mathbf{0}}$ & Inclinação maior que $\mathbf{1 5}^{\mathbf{0}}$ \\
\hline $\mathrm{e} \geq 50 \mathrm{~cm}$ & 0,1 & - \\
$25 \leq \mathrm{e}<50$ & 0,2 & - \\
$15 \leq \mathrm{e}<25$ & 0,3 & - \\
$10 \leq \mathrm{e}<15$ & 0,4 & 0,5 \\
$6 \leq \mathrm{e}<10$ & 0,5 & 0,6 \\
$4 \leq \mathrm{e}<6$ & 0,6 & 0,7 \\
$2 \leq \mathrm{e}<4$ & 0,7 & 0,8 \\
\hline
\end{tabular}

Fonte: adaptado de FLL (2002 ${ }^{2}$ apud OHNUMA, 2008).

Figura 2 - Modelo esquemático da estrutura do telhado verde

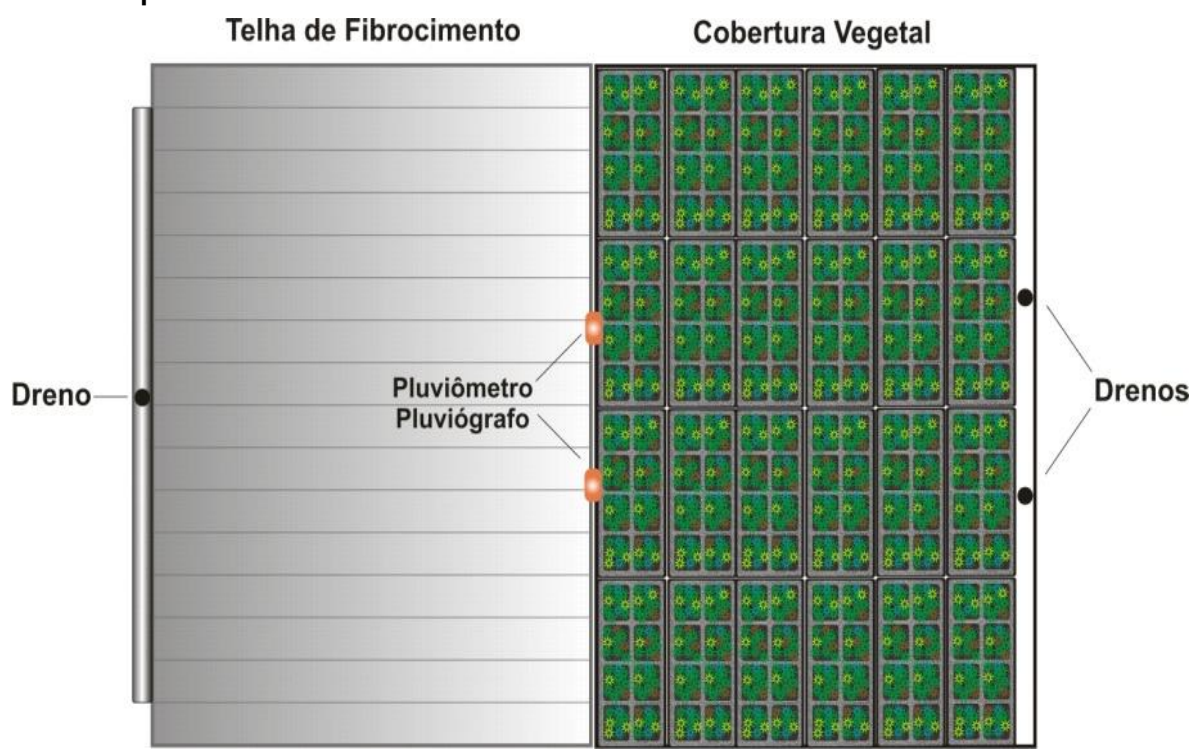

Figura 3 - Sistema modular com (a) galocha do telhado verde, (b) esquema vertical e (c) vista superior

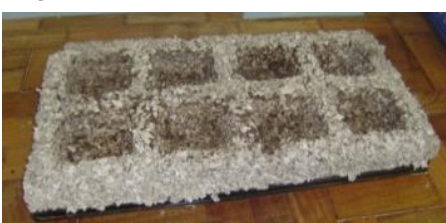

(a)

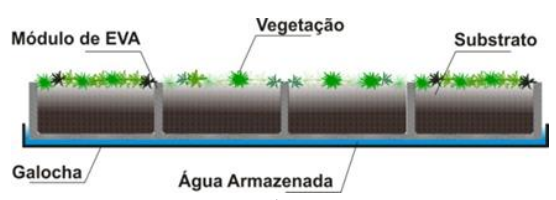

(b)

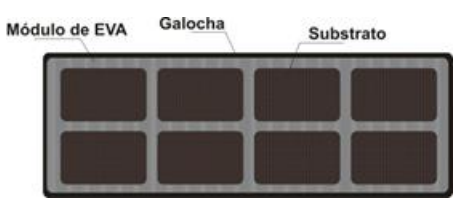

(c)

${ }^{2}$ FORSCHUNGSGESELLSCHAFT LANDSCHAFTSENTWICKLUNG LANDSCHAFTSBAU. Richtlinie fur die Planung, Ausfuhrung und Pflege von Dachbegrunungen. Bonn, 2002.

144 Tassi, R.; Tassinari, L. C. da S.; Piccilli, D. G. A.; Persch, C. G. 
Figura 4 - Vista do experimento implantado

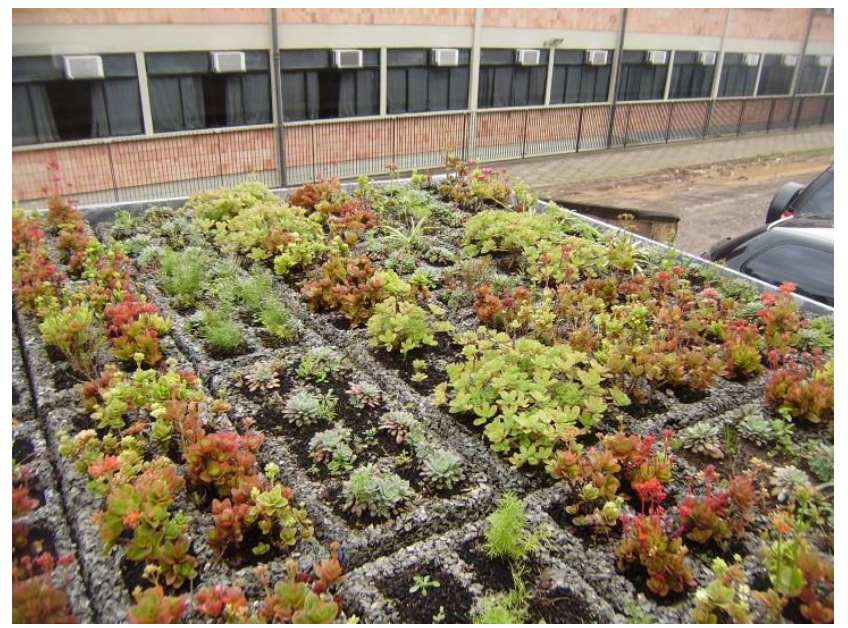

Para a coleta e monitoramento dos volumes escoados, foram instalados em ambos os telhados drenos na extremidade inferior da estrutura de suporte (ver Figura 2 e Figura 5), de forma que todo o escoamento excedente da precipitação seja drenado para seu interior. A partir dos drenos, a água é derivada para uma tubulação vertical e conduzida até reservatórios de polietileno de $500 \mathrm{~L}$ cada, instalados sob o telhado. O volume de $500 \mathrm{~L}$ foi determinado a partir da análise de chuvas intensas da cidade, dada pela equação IDF local (BELINAZO, 1991), para um período de recorrência de 10 anos. O volume drenado a partir de cada um dos telhados foi reservado, e o aumento do nível no interior dos reservatórios registrado a cada $2 \mathrm{~min}$, por meio da utilização de sensores de nível, ligados a um datalogger que registra os dados medidos.

Para o monitoramento da precipitação, foram instalados um pluviômetro e um pluviógrafo exatamente no centro da estrutura do telhado, o que permitiu a determinação do volume total de chuva incidente em cada evento.

Para a cobertura vegetal, inicialmente foram aplicadas duas espécies, conhecidas popularmente por gazânia (Gazania rigens) e kalanchoe (Kalanchoe blossfeldiana). Já no primeiro mês de monitoramento, em razão da mortalidade de $100 \%$ das gazânias, foram introduzidas quatro novas espécies (SILVA, 2010), conhecidas como falsoboldo (Plectranthus barbatus), gravatinha (Chlorophytum comosum), aspargo palito (Asparagus-densiflorus 'sprengeri') e echeveria (Echeveria). As espécies foram distribuídas de maneira uniforme dentro do mesmo módulo, mas foi feita uma homogeneização entre eles, conforme se pode identificar na Figura 4. Durante o período de monitoramento, o telhado verde não recebeu qualquer tipo de irrigação, para não afetar as estimativas de evapotranspiração e armazenamento das plantas e do módulo respectivamente.

\section{Métodos}

\section{Monitoramento}

Para fins de consistência, os volumes de chuva registrados no pluviômetro e no pluviógrafo foram comparados com os registrados em um pluviógrafo do Instituto Nacional de Meteorologia (Inmet), localizado a aproximadamente $1,5 \mathrm{~km}$ do módulo experimental. Do posto do Inmet também foram obtidos outros dados climatológicos, como médias de temperatura, umidade, radiação e velocidade do vento, dados esses utilizados para avaliar as condições climáticas e estimativas da evapotranspiração. A evapotranspiração foi estimada pela equação de Penman (TUCCI; BELTRAME, 1993) e utilizada no modelo matemático, conforme será posteriormente descrito.

Com relação ao monitoramento do nível no interior dos reservatórios, além do registro dos sensores, ao final de cada evento chuvoso era realizada uma leitura manual para corroborar os dados fornecidos pelo sensor, permitindo, assim, a detecção de eventuais falhas de leitura dele.

Após cada evento chuvoso, cada um dos reservatórios era aberto, toda a água armazenada era eliminada, e o reservatório lavado e preparado para o próximo evento. A variação temporal do nível permitiu determinar os hidrogramas correspondentes para o evento. No final do período do monitoramento, foi possível contar com 43 eventos. 
Figura 5 - Esquema do sistema de monitoramento empregado

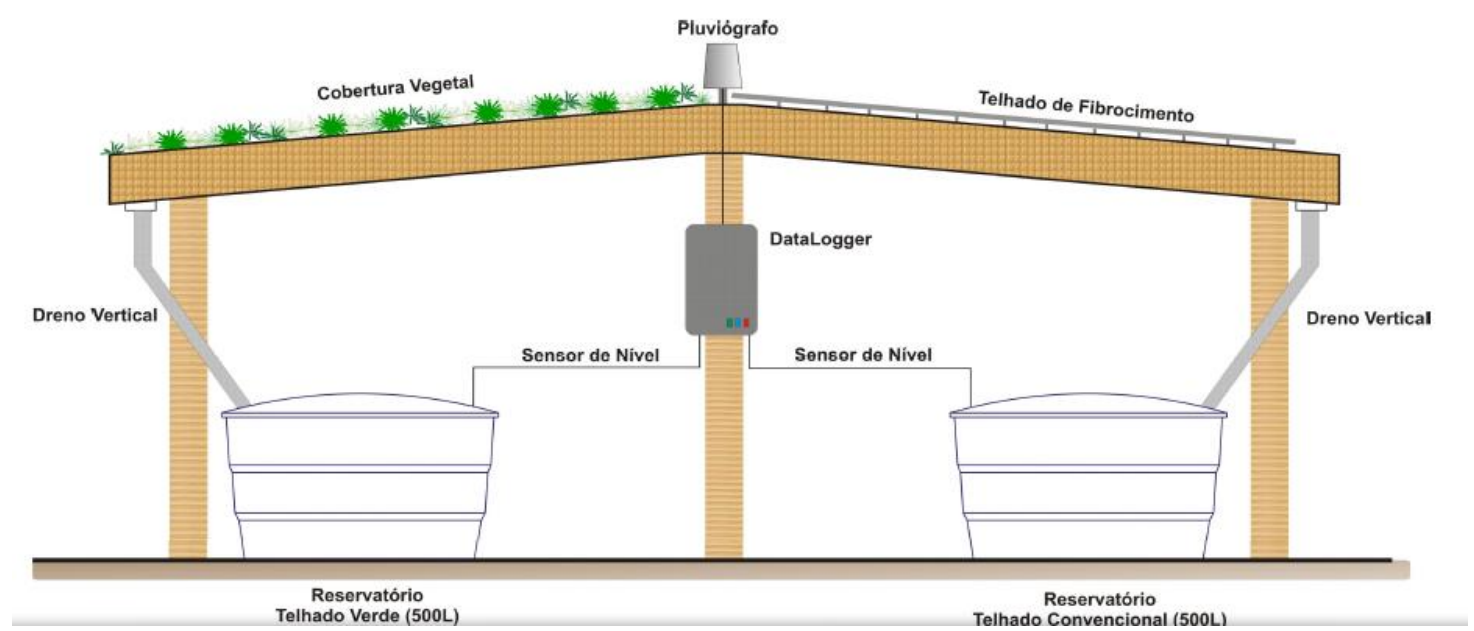

\section{Tratamento dos dados}

Os dados de precipitação e volume foram utilizados para a determinação do coeficiente de escoamento em cada um dos telhados (telhado verde e telhado convencional) e realização de um balanço hídrico simplificado, de forma a identificar os volumes máximos armazenados na cobertura verde em cada um dos eventos e verificar sua eficiência no controle quantitativo do escoamento pluvial. Posteriormente, o resultado do monitoramento foi utilizado para calibrar o modelo de balanços utilizado.

Considerando a precipitação monitorada e os volumes escoados para cada reservatório, foi determinado o coeficiente de escoamento superficial (C) de ambos os telhados (Equação 1). Como esse parâmetro reflete a capacidade do telhado verde no controle quantitativo do escoamento, baixos valores de $\mathrm{C}$ indicam que uma maior parcela de chuva fica retida no telhado (alta eficiência), enquanto valores elevados demonstram que praticamente toda a precipitação é escoada (baixa eficiência).

$C=\frac{\text { volume escoado superficialmente }}{\text { volume precipitado }}$

Eq. 1

Sendo C adimensional, e os volumes escoado superficialmente e precipitado informados na mesma unidade.

Os registros de variação de nível foram utilizados para a identificação do início do escoamento no telhado verde e no telhado convencional. O tempo de retardo do escoamento foi determinado avaliando-se a diferença entre o início do escoamento do telhado verde e do telhado convencional.

\section{Modelagem}

De maneira a avaliar o comportamento do telhado verde ante precipitações com magnitudes não monitoradas, além de ampliar o conhecimento de seu comportamento para uma série de eventos de longo prazo, foi desenvolvido um modelo matemático simplificado. A aplicação do modelo se deu em duas etapas: calibração aos dados e aplicação para prognóstico.

A equação básica desse modelo baseia-se em um balanço simplificado de volumes, onde se considera que o volume escoado superficialmente (Q) é dado pelo resultado da subtração da precipitação total $(\mathrm{P})$ pelo armazenamento de água no telhado verde (S) e pela perda de água por evapotranspiração (EVT), resultando na Equação 2.

$Q=P-S-E V T$

Eq. 2

Sendo todas as unidades em milímetros.

A parcela de armazenamento (S) inclui a capacidade do telhado verde em armazenar água no substrato (solo), no elemento drenante (galocha) e plantas (interceptação). O montante que engloba o armazenamento no solo e galocha refere-se à água que permanece retida no módulo do telhado verde. A parcela de interceptação representa a água retida pela vegetação e é intrinsecamente dependente do tipo e da sanidade da cobertura vegetal aplicada. Esses fatores foram unidos em uma variável apenas, em função de dificuldade de medir a influência de cada um separadamente. Contudo, conforme observações durante o monitoramento e resultados obtidos por outros pesquisadores (CARTER; BUTLER, 2008), o fenótipo das plantas empregadas em telhados verdes extensivos não exerce função significativa

146 Tassi, R.; Tassinari, L. C. da S.; Piccilli, D. G. A.; Persch, C. G. 
na interceptação, sendo praticamente desprezível, diante de outros processos.

Uma vez definido o modelo matemático, este foi calibrado considerando o produto do monitoramento de 17 meses, que contou com 43 eventos chuvosos com precipitações de diferentes características, retratando-se distintas épocas do ano. Durante a calibração, as variáveis $\mathrm{P}, \mathrm{S}$ e EVT foram introduzidas no modelo, de maneira a reproduzir o valor de Q monitorado.

Com base nos resultados do monitoramento, foi determinado um valor médio para o armazenamento de água no telhado verde $(\mathrm{S})$. Esse valor foi utilizado como tentativa inicial de calibração do modelo. No entanto, durante a modelagem, o armazenamento foi ajustado de forma a minimizar o erro entre o volume escoado calculado e o observado. A medida estatística empregada para verificar a consistência dos volumes foi uma função de $\mathrm{R}^{2}$. A EVT foi calculada pela equação de Penman, considerando os dados da estação climatológica do Inmet, localizada próxima ao experimento. $\mathrm{O}$ monitoramento do pluviógrafo forneceu o valor de P.

Uma vez feita a calibração do modelo aos eventos observados, estendeu-se a análise do comportamento do telhado verde para uma série contínua de chuva diária, obtida junto ao Inmet, desde o mês de janeiro de 2005 até Aabril de 2010. Portanto, a modelagem realizada para o cálculo do volume armazenado pelo telhado verde, para os distintos eventos de precipitação em um dia qualquer $(\mathrm{t})$, pode ser representada pelo esquema da Figura 6, onde P é o volume total precipitado, S o volume armazenado no telhado verde, Smáx é a capacidade máxima de armazenamento de água no telhado verde, EVT, a evapotranspiração, e Vesc é o volume resultante do escoamento superficial no telhado.

Conforme se observa no fluxograma, o armazenamento $\mathrm{S}$ em um intervalo de tempo $\mathrm{t}+1$ é dado pelo volume de precipitação $\mathrm{P}_{\mathrm{t}+1}$, somado à parcela $\mathrm{S}$ armazenada no instante $\mathrm{t}$ subtraída das parcelas de evapotranspiração $E \mathrm{TT}_{\mathrm{t}+1}$ e de escoamento superficial Vesc ${ }_{t+1}$. Se $P_{t+1}+S_{t}+$ $\mathrm{EVT}_{\mathrm{t}+1} \leq \mathrm{S}_{\text {máx }}\left(\mathrm{S}_{\text {máx }}\right.$ representa a capacidade máxima de armazenamento de água no telhado verde), Vesc $_{t+1}$ será nulo, pois todo volume acaba sendo armazenado no telhado. Para $\mathrm{P}_{t+1}+\mathrm{S}_{t}+$ $\mathrm{EVT}_{\mathrm{t}+1}>\mathrm{S}_{\text {máx }}$, haverá volume escoado.

\section{Resultados}

\section{Eficiência do telhado verde a partir do monitoramento}

Os resultados obtidos a partir do monitoramento mostram que, com relação aos aspectos quantitativos, o telhado verde conseguiu reduzir significativamente o escoamento pluvial, comparativamente ao telhado convencional (Figura 7).

É possível verificar na Figura 7 o volume total de chuva em cada um dos 43 eventos analisados e o coeficiente de escoamento (C) do telhado verde, que esteve sempre abaixo daquele obtido para o telhado convencional para um mesmo evento chuvoso. Para alguns eventos $(2,8,13,14,18,23$, 35 e 36), o telhado verde conseguiu armazenar todo o volume precipitado $(\mathrm{C}=0)$. Em média, apenas $38 \%$ do volume total de chuva que incidiu no telhado verde resultou em escoamento, contra os $87 \%$ do telhado convencional, mostrando que, mesmo parcialmente, foi possível controlar o escoamento pluvial, promovendo uma redução dos volumes escoados da ordem de $56 \%$. A capacidade média de armazenamento de água no telhado verde foi de $12,1 \mathrm{~mm} / \mathrm{m}^{2}$, o que resultaria em um volume de água retido de aproximadamente 73 litros. Na Tabela 2 são apresentadas as características dos eventos, incluindo os valores de intensidade média da chuva durante o evento chuvoso, e a maior intensidade (crítica) dentro da duração do evento, onde é possível verificar que maiores intensidades de chuva não produzem, necessariamente, condições para o aumento do escoamento superficial, estando estes mais relacionados ao volume total de chuva ou condições de umidade do solo, como discutido na sequência.

Comparativamente com o telhado convencional, o telhado verde reduziu, em média, $62 \%$ dos volumes escoados superficialmente, além de promover o retardo no início do escoamento superficial. $\mathrm{O}$ valor corrobora o encontrado em um estudo realizado na Carolina do Norte, Estados Unidos, com sistema modular similar, que resultou na redução média de $60 \%$ dos volumes escoados (MORAN, 2004). O valor obtido também é bastante similar ao encontrado em um estudo com telhado verde extensivo na cidade de Porto Alegre, RS (com condições climáticas semelhantes àquelas do experimento), embora com sistema construtivo diferenciado (CASTRO; GOLDENFUM, 2010). 
Figura 6 - Fluxograma esquemático do modelo de balanço hídrico do telhado verde

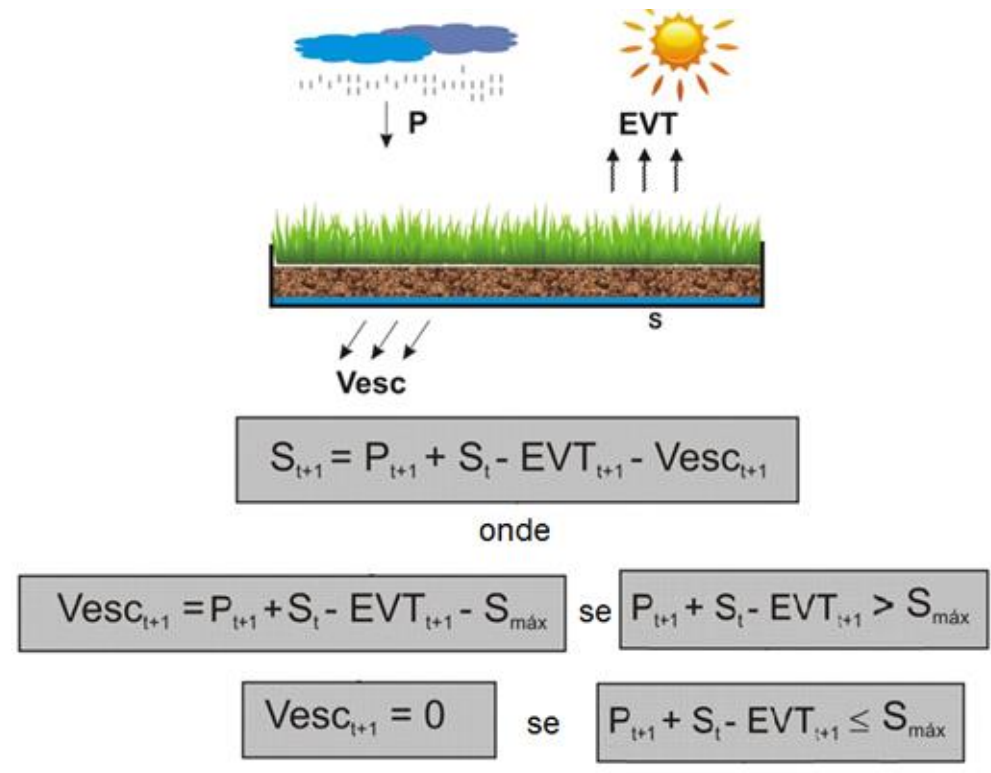

Figura 7 - Avaliação do controle quantitativo do escoamento superficial no telhado verde e do telhado convencional

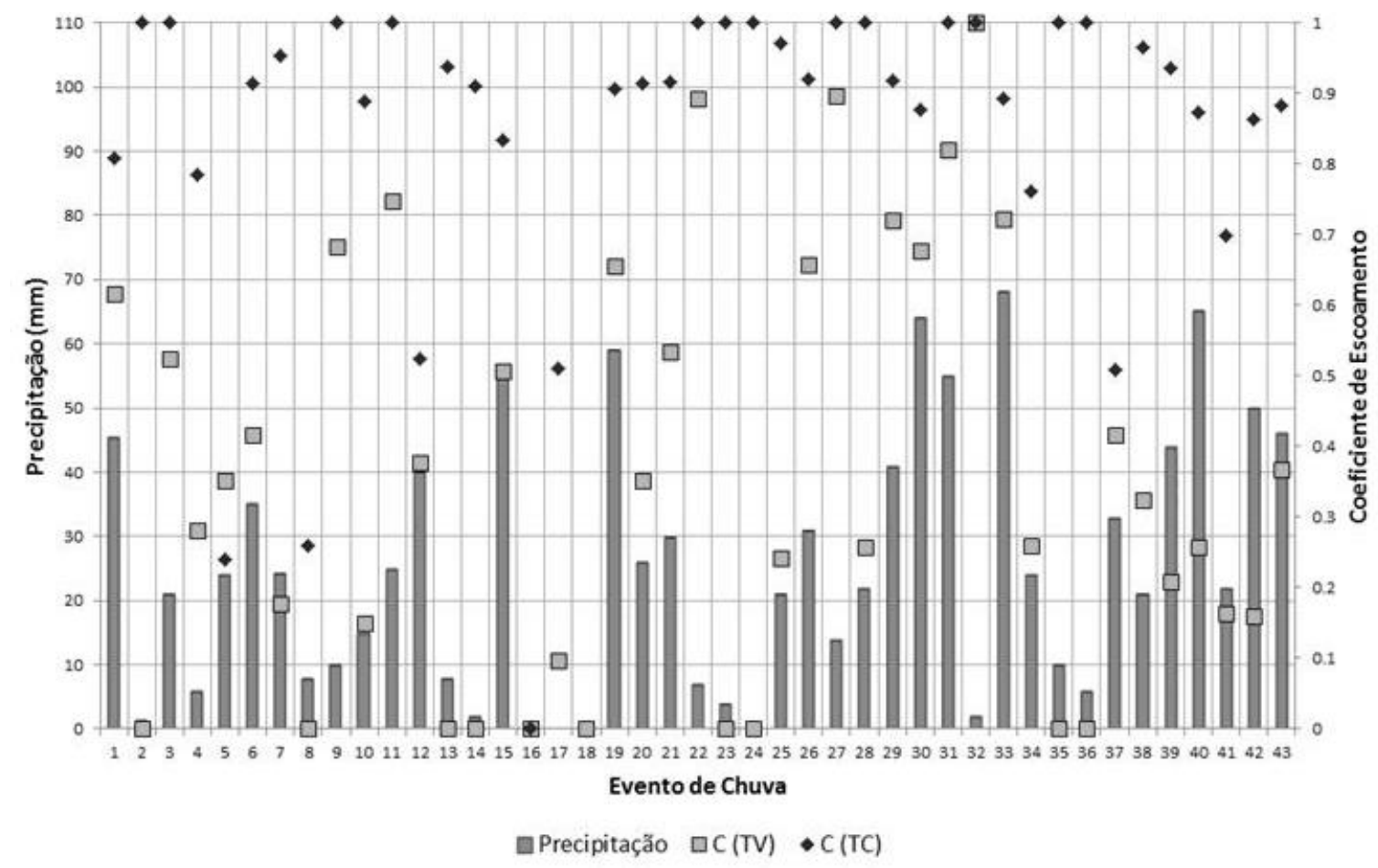

Uma das hipóteses acerca da eficiência obtida no telhado verde está relacionada com a disponibilidade de água no substrato e sua capacidade de interferir no maior ou menor armazenamento de água durante o evento chuvoso. Portanto, foi realizada uma análise para investigar possíveis efeitos da condição de Umidade Antecedente do Solo (UAS) na eficiência do telhado verde, já que eventos de magnitudes muito semelhantes, a exemplo dos eventos 8-22 e 29-39, resultaram em valores de $\mathrm{C}$ bastante diferentes. Essa análise foi realizada por meio da identificação do volume de chuva ocorrido nos cinco dias (P5) que antecedem o evento chuvoso monitorado, seguindo os valores de referência para culturas estabelecidas, conforme recomendados pelo SCS (1971): $\mathrm{UAS}=\mathrm{I}$ para $\mathrm{P} 5 \leq 13 \mathrm{~mm}$; UAS $=$ II para 13 $\mathrm{mm}<\mathrm{P} 5 \leq 28 \mathrm{~mm}$; e UAS $=$ III para $\mathrm{P} 5>28 \mathrm{~mm}$. Os 
resultados dessa análise são apresentados na Tabela 2.

Identificou-se que a grande maioria dos eventos monitorados encontra-se na UAS=III (44\%), enquanto os eventos nas classes $\mathrm{UAS}=\mathrm{I}$ e UAS=II resultaram em $28 \%$ cada um. O resultado da análise do valor de $\mathrm{C}$ para os eventos em cada UAS é apresentado na Tabela 3, onde também são apresentados os limites superior e inferior esperados para o valor de $\mathrm{C}$ em cada UAS, considerando uma distribuição normal, com significância de 5\% (confiança de 95\%).

Tabela 2 - UAS e sua relação com as características do evento chuvoso monitorado

\begin{tabular}{|c|c|c|c|c|c|c|c|}
\hline Evento & Data & $\begin{array}{c}\text { Intensidade } \\
(\mathrm{mm} / \mathrm{h})\end{array}$ & $\begin{array}{c}\text { Intensidade } \\
\text { crítica }(\mathrm{mm} / \mathrm{h})\end{array}$ & $\begin{array}{c}\text { Precipitação } \\
\text { total }(\mathbf{m m})\end{array}$ & $\begin{array}{l}\text { P5 dias } \\
(\mathrm{mm})\end{array}$ & UAS & C (TV) \\
\hline 1 & $24 / 11 / 10$ & 5,0 & 15,2 & 45,4 & 8,2 & $\bar{I}$ & 0,62 \\
\hline 2 & $2 / 12 / 10$ & 0,7 & 1,2 & 1,4 & 0,2 & I & 0,00 \\
\hline 3 & $2 / 12 / 10$ & 10,5 & 20,4 & 21,0 & 1,6 & I & 0,53 \\
\hline 4 & $11 / 12 / 10$ & 7,0 & 7,0 & 6,0 & 7,0 & I & 0,28 \\
\hline 5 & $13 / 12 / 10$ & 1,4 & 3,8 & 24,0 & 31,4 & III & 0,35 \\
\hline 6 & $20 / 12 / 10$ & 2,5 & 15,8 & 35,0 & 34,4 & III & 0,42 \\
\hline 7 & 8/1/11 & 3,7 & 10,0 & 24,2 & 13,0 & II & 0,18 \\
\hline 8 & $12 / 1 / 11$ & 5,1 & 5,6 & 8,0 & 12,8 & I & 0,00 \\
\hline 9 & $28 / 1 / 11$ & 4,0 & 7,6 & 10,0 & 47,6 & III & 0,68 \\
\hline 10 & $1 / 2 / 11$ & 8,4 & 16,6 & 15,0 & 24,8 & II & 0,15 \\
\hline 11 & $4 / 2 / 11$ & 11,0 & 18,8 & 25,0 & 40,4 & III & 0,75 \\
\hline 12 & $10 / 2 / 11$ & $* *$ & $* *$ & 40,0 & 40,2 & III & 0,38 \\
\hline 13 & 18/3/11 & 1,1 & 4,6 & 8,0 & 12,0 & I & 0,00 \\
\hline 14 & $25 / 3 / 11$ & 0,4 & 0,6 & 2,0 & 0,6 & I & 0,00 \\
\hline 15 & $28 / 3 / 11$ & 1,0 & 5,0 & 56,0 & 46,2 & III & 0,51 \\
\hline 16 & $1 / 4 / 11$ & 0,2 & 0,2 & 0,2 & 21,6 & II & 0,00 \\
\hline 17 & $16 / 4 / 11$ & 4,0 & 4,0 & 4,6 & 117,0 & III & 0,10 \\
\hline 18 & $18 / 4 / 11$ & $* *$ & $* *$ & 4,8 & 114,4 & III & 0,00 \\
\hline 19 & $25 / 4 / 11$ & $* *$ & $* *$ & 59,0 & 56,4 & III & 0,66 \\
\hline 20 & $2 / 5 / 11$ & $* *$ & $* *$ & 26,0 & 20,0 & II & 0,35 \\
\hline 21 & $11 / 5 / 11$ & 2,6 & 7,8 & 30,0 & 34,4 & III & 0,53 \\
\hline 22 & $12 / 5 / 11$ & 2,8 & 6,2 & 7,0 & 43,0 & III & 0,89 \\
\hline 23 & $23 / 05 / 11$ & 0,6 & 1,0 & 4,0 & 4,8 & I & 0,00 \\
\hline 24 & $3 / 6 / 11$ & 0,2 & 0,2 & 0,2 & 0,8 & I & 0,00 \\
\hline 25 & $8 / 6 / 11$ & 1,3 & 3,2 & 21,0 & 24,4 & II & 0,24 \\
\hline 26 & $21 / 6 / 11$ & 3,6 & 11,2 & 31,0 & 67,4 & III & 0,66 \\
\hline 27 & $27 / 6 / 11$ & $* *$ & $* *$ & 14,0 & 16,8 & II & 0,90 \\
\hline 28 & 14/7/11 & $* *$ & $* *$ & 22,0 & 0 & I & 0,26 \\
\hline 29 & $21 / 7 / 11$ & $* *$ & $* *$ & 41,0 & $*$ & I & 0,72 \\
\hline 30 & $28 / 7 / 11$ & $* *$ & $* *$ & 64,0 & 35,0 & III & 0,68 \\
\hline 31 & $2 / 8 / 11$ & $* *$ & $* *$ & 55,0 & 3,8 & III & 0,82 \\
\hline 32 & $3 / 8 / 11$ & $* *$ & $* *$ & 2,0 & 55,0 & III & 1,00 \\
\hline 33 & $9 / 8 / 11$ & $* *$ & $* *$ & 68,0 & 24,4 & II & 0,72 \\
\hline 34 & 15/8/11 & 1,9 & 6,2 & 24,0 & 19,2 & II & 0,26 \\
\hline 35 & 19/8/11 & 1,2 & 4,4 & 10,0 & 21,4 & II & 0,00 \\
\hline 36 & $23 / 8 / 11$ & 0,9 & 1,6 & 6,0 & 17,2 & II & 0,00 \\
\hline 37 & $31 / 8 / 11$ & 1,7 & 9,8 & 33,0 & 27,2 & II & 0,42 \\
\hline 38 & $6 / 9 / 11$ & 1,7 & 7,4 & 21,0 & 21,6 & II & 0,33 \\
\hline 39 & 21/9/11 & 2,0 & 10,2 & 44,0 & 42,6 & III & 0,21 \\
\hline 40 & $3 / 10 / 11$ & 3,6 & 16,4 & 65,0 & 57,0 & III & 0,26 \\
\hline 41 & $6 / 10 / 11$ & 5,4 & 10,6 & 22,0 & 11,2 & I & 0,16 \\
\hline 42 & $25 / 10 / 11$ & 5,0 & 18,4 & 50,0 & 50,0 & III & 0,16 \\
\hline 43 & $26 / 10 / 11$ & 3,1 & 18,0 & 46,0 & 99,0 & III & 0,37 \\
\hline
\end{tabular}

Nota: * Não foi possível determinar, devido a falhas no monitoramento; ** pluviógrafo fora de operação. 
Tabela 3 - Estatísticas dos valores de C para cada UAS dos eventos monitorados

\begin{tabular}{c|c|c|c}
\hline Estatísticas de C & UAS-I & UAS-II & UAS-III \\
\hline Menor valor & 0,00 & 0,00 & 0,00 \\
Média & 0,21 & 0,30 & 0,50 \\
Maior valor & 0,72 & 0,90 & 1,00 \\
Desvio padrão & 0,26 & 0,27 & 0,27 \\
Faixa de valores para 95\% de confiança & $0,07-0,36$ & $0,14-0,45$ & $0,37-0,62$ \\
\hline
\end{tabular}

Figura 8 - Coeficiente de escoamento médio dos eventos simulados para as estações do ano

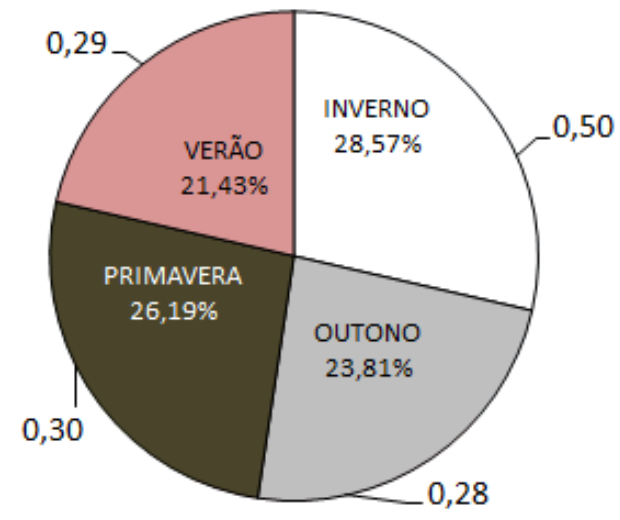

A eficiência do telhado verde mostrou-se sensível à UAS, à medida que houve um aumento de $\mathrm{C}$ (média e maior valor) para as condições de maior disponibilidade de água no solo (UAS-II e UASIII). Por exemplo, embora o volume de chuva de 2 mm ocorrido no evento 32, no dia 03/08/2011, seja pouco significativo, a P5 de $55 \mathrm{~mm}$ acumulada foi suficiente para reduzir totalmente a capacidade de armazenamento de água no telhado verde, fazendo com que todo volume precipitado escoasse.

Alguns resultados também indicaram que, embora pertencente a uma mesma classe de UAS e com volume de chuva similar, o coeficiente de escoamento resultou significativamente diferente, como é o caso dos eventos 18 e 32. Para melhor investigar essas diferenças e avaliar possíveis impactos das condições climatológicas, os eventos foram separados e analisados, considerando as quatro estações do ano. A Figura 8 mostra os resultados dessa análise, onde é possível verificar que houve uma boa distribuição amostral ao longo das estações, com coeficiente de escoamento resultando em maior valor durante o inverno $(0,50)$. Durante as demais estações a eficiência do telhado verde foi muito semelhante. Durante o período de monitoramento, foram registradas temperaturas que variaram entre $0,2{ }^{\circ} \mathrm{C}$ (mínima) e $38{ }^{\circ} \mathrm{C}$ (máxima), com ocorrência de estiagem bastante prolongada durante o verão, e frio intenso durante o inverno. As precipitações médias acumuladas durante esses períodos foram de 255,4, 336,406 e $153,8 \mathrm{~mm}$ para a sequência primavera, verão, outono e inverno.
No verão, por exemplo, embora o volume de chuva observado seja superior ao do inverno, a geração de escoamento superficial é significativamente inferior. Portanto, os resultados desta segunda análise reforçam a suspeita de que a eficiência do telhado verde no controle quantitativo do escoamento pluvial é influenciada pela umidade disponível no solo e pelas condições climáticas, responsáveis pelas taxas de evapotranspiração.

Com relação à análise dos hidrogramas resultantes do escoamento no telhado verde, em comparação ao telhado convencional, verificou-se que o telhado verde promoveu um retardo no início do escoamento, quando comparado com o telhado convencional.

\section{Modelagem do telhado verde}

O modelo desenvolvido, embora simplificado, permitiu a realização de uma boa calibração aos eventos observados (Figura 9), com um coeficiente de determinação de $84 \%$. Portanto, considerou-se que atende aos propósitos da simulação de uma série de precipitação de longo período, podendo ser utilizado para um prognóstico do comportamento do telhado verde em longo prazo.

Aplicando-se o modelo para a série de longo período (2005-2010), que resultou em 269 eventos, o coeficiente de escoamento médio foi de 0,25 $(25 \%)$, mostrando uma eficiência no controle do escoamento superficial superior àquela encontrada para os eventos monitorados (40\%), com uma

150 Tassi, R.; Tassinari, L. C. da S.; Piccilli, D. G. A.; Persch, C. G. 
redução de aproximadamente $38 \%$. Nessa situação mais representativa, portanto, os resultados indicaram que apenas um quarto do total de chuva precipitada durante o período geraria escoamento superficial, mostrando a eficiência do telhado verde no controle do escoamento pluvial. O armazenamento médio simulado no telhado verde foi de $12,6 \mathrm{~mm} / \mathrm{m}^{2}$, de acordo com o valor observado durante o monitoramento. De maneira a permitir aferir o resultado do prognóstico realizado, o experimento continua sendo monitorado, para verificar se possíveis mudanças (composição vegetal, perda de solo, etc.) podem conduzir a diferenças significativas nos resultados obtidos.

Do total de eventos simulados, $68 \%$ encontram-se na UAS-I, $22 \%$ na UAS-III e $10 \%$ na UAS-II. A análise do valor de $\mathrm{C}$ para os eventos em cada
UAS é apresentada na Tabela 4. Na mesma tabela também são apresentados os limites superior e inferior esperados para o valor de $\mathrm{C}$ em cada UAS, considerando uma distribuição normal, com significância de 5\% (confiança de 95\%).

Embora a classe de UAS-I seja a mais representativa, os resultados mostraram o mesmo padrão de comportamento daqueles obtidos para os eventos monitorados, com perda de eficiência do telhado verde à medida que aumenta a umidade do solo.

Com relação à influência de condições climáticas (Tabela 5), o agrupamento dos resultados por estação revelou que, de fato, além da UAS, o inverno apresenta-se como a condição crítica para a eficiência do telhado verde, tendo sido verificado o aumento de $\mathrm{C}$.

Figura 9 - Relação entre volume escoado observado e calculado durante a calibração do modelo

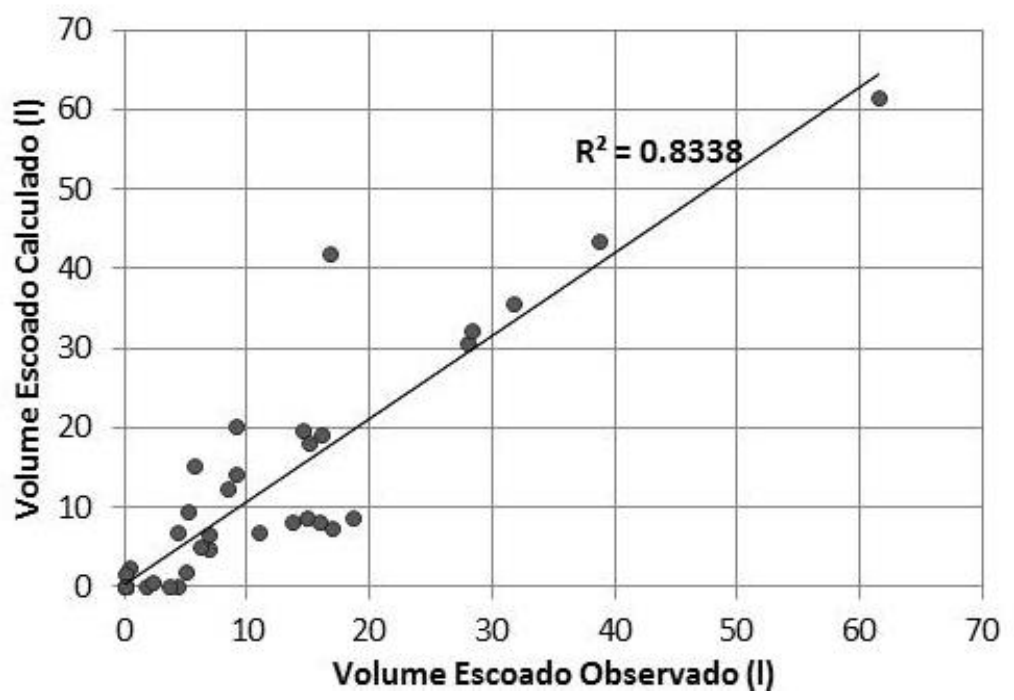

Tabela 4 - Estatísticas de C para cada uma das UAS dos eventos simulados

\begin{tabular}{c|c|c|c}
\hline Estatísticas de C & UAS-I & UAS-II & UAS-III \\
\hline Menor valor & 0,00 & 0,00 & 0,00 \\
Média & 0,24 & 0,19 & 0,31 \\
Maior valor & 0,88 & 0,88 & 0,87 \\
Desvio padrão & 0,29 & 0,30 & 0,33 \\
Faixa de valores para 95\% de confiança & $0,20-0,28$ & $0,07-0,3$ & $0,23-0,40$ \\
\hline
\end{tabular}

Tabela 5 - Estatísticas de C para os eventos simulados de acordo com as estações do ano

\begin{tabular}{c|c|c|c|c}
\hline & Primavera & Verão & Outono & Inverno \\
\hline $\mathrm{N}^{\text {o de eventos }}$ & 67 & 55 & 77 & 70 \\
$\mathrm{Menor} \mathrm{valor}^{\text {Média }}$ & 0,00 & 0,00 & 0,00 & 0,00 \\
Maior valor & 0,23 & 0,23 & 0,23 & 0,31 \\
Desvio padrão & 0,87 & 0,82 & 0,88 & 0,84 \\
Faixa de valores para 95\% de confiança & 0,30 & 0,29 & 0,31 & 0,31 \\
\hline
\end{tabular}




\section{Considerações finais}

O presente trabalho apresentou os resultados de um estudo conduzido para avaliar a eficiência de um telhado verde no controle quantitativo do escoamento pluvial, baseando-se em técnicas de monitoramento e de modelagem. Para isso, foi construído um protótipo de telhado verde extensivo com área de $6 \mathrm{~m}^{2}$, monitorado com auxílio de pluviógrafo, pluviômetro e sensor de nível. Um telhado com telhas de fibrocimento de igual área e demais características também foi construído, de maneira a permitir comparação dos resultados.

O período de monitoramento compreendeu 17 meses, e foi possível captar a variabilidade climática das estações. Durante esse período, verificou-se que, comparativamente ao telhado convencional, foi possível reduzir, em média, $62 \%$ dos volumes escoados superficialmente com a utilização do telhado verde, além de promover o retardo no início do escoamento superficial.

Complementarmente ao monitoramento, uma simulação foi realizada a partir de um modelo de balanço de volumes, calibrado para os dados monitorados, e aplicado para uma série diária de dados de 6 anos (2005-2010), com um total de 269 eventos simulados. Para esses eventos, foi possível uma redução média dos volumes escoados de aproximadamente $75 \%$.

O monitoramento também revelou que a capacidade de armazenamento média de água no telhado verde implantado corresponde a cerca de $12,1 \mathrm{~mm} / \mathrm{m}^{2}$, sendo diretamente afetada pelas condições climáticas e de umidade antecedente do solo. A estação climática em que o telhado verde apresentou menor eficiência foi o inverno, e sob condições de elevada presença de água no substrato. De qualquer forma, a capacidade de armazenamento encontrada é bastante significativa, considerando que o substrato possui apenas $8 \mathrm{~cm}$ de espessura. Outros autores, a exemplo de Mendiondo e Cunha (2004), conseguiram uma capacidade de armazenamento média de $14 \mathrm{~mm} / \mathrm{m}^{2}$ em um telhado com substrato de $15 \mathrm{~cm}$, instalado e monitorado durante um mês na cidade de São Carlos, SP, no qual o maior volume de chuva observado foi de aproximadamente $35 \mathrm{~mm}$.

Esses resultados traduzem a eficiência do telhado verde no controle quantitativo do escoamento superficial e reforçam a necessidade de incentivos para sua utilização em centros urbanos, considerando a ótica do desenvolvimento de baixo impacto. Além de contribuir para a redução do volume das águas pluviais direcionadas para as redes de drenagem, o que reduz o custo de implantação delas, a utilização do telhado verde fornece outros benefícios não avaliados neste estudo, mas citados por outros pesquisadores, a exemplo do conforto térmico e acústico.

\section{Referências}

ARENDT, R. Linked Landscapes: creating greenway corridors through conservation subdivision design strategies in the northeastern and central United States. Landscape and Urban Planning, v. 68, n. 2, p. 241- 269, 2004.

BALDESSAR, S. M. N. Telhado Verde e Sua Contribuição na Redução da Vazão da Água Pluvial Escoada. Curitiba, 2012. 124 f. Dissertação (Mestrado em Engenharia Civil) Programa de Pós-Graduação em Engenharia de Construção Civil, Universidade Federal do Paraná, Curitiba, 2012.

BELINAZO, H. J. Metodologia Computacional Para Análise das Chuvas Intensas: desenvolvimento e aplicação aos dados de Santa Maria - RS. Santa Maria, 1991. Dissertação (Mestrado em Engenharia Agrícola) - Escola de Engenharia, Universidade Federal de Santa Maria, Santa Maria, 1991.

BEYER, P. O. Relatório Técnico: medição do desempenho térmico de Ecotelhas. Laboratório de Vapor e Refrigeração. Departamento de Engenharia Mecânica. Universidade Federal do Rio Grande do Sul, 2007.

BRAGA, R.; CARVALHO, P. F. C. Recursos Hídricos e Planejamento Urbano e Regional. Rio Claro: Laboratório de Planejamento Municipal, 2003. p. 113-127.

CARTER, T.; BUTLER, C. Ecological Impacts of Replacing Traditional Roofs With Green Roofs in Two Urban Areas. Cities and the Environment, v. 1, n. 2, 2008.

CASTRO, A. S.; GOLDENFUM, J. A. Uso de Telhados Verdes no Controle Quantitativo do Escoamento Superficial Urbano. Atitude, Construindo Oportunidades: revista de divulgação científica da Faculdade Dom Bosco de Porto Alegre, Porto Alegre, v. 4, n. 7, p. 75-81, 2010.

CLARK, S. E. et al. Infiltration vs. Surfasse Water Discharge: guidance for stormwater managers. London: IWA Publishing, 2006.

CLARKE, R.; KING, J. O Atlas da Água. São Paulo: Publifolha, 2005. 
COSTA, J.; COSTA, A.; POLETO, C. Telhado Verde: redução e retardo do escoamento superficial. Revista de Estudos Ambientais, v. 14, n. 2, edição especial, p. 50-56, 2012.

GIBBS, J. et al. Evaluating Performance of a Green Roof System With Different Growing Mediums, Sedum Species and Fertilizer Treatments. In: ILLINOIS STATE ACADEMY OF SCIENCE ANNUAL METTING, Chicago, 2006. Proceedings... Chicago, 2006.

HENEINE, M. C. A. S. Cobertura Verde. 2008. 49 f. Monografia (Especialização em Engenharia Civil) - Escola de Engenharia, Universidade Federal de Minas Gerais, Belo Horizonte, 2008.

INSTITUTO BRASILEIRO DE GEOGRAFIA E ESTATÍSTICA. Censo Demográfico 2010. 2010. Disponível em:

http://www.ibge.gov.br/home/estatistica/populacao /censo2010/default.shtm. Acesso em: 10 jul. 2013.

HYDROTEC MEMBRANE CORPORATION. Garden Roof Planning Guide. Canadá, 2007. 19 p.

KAUSHAL, S. et al. Effects of Stream Restoration on Denitrification in an Urbanizing Watershed. Ecological Applications, v. 18, n. 3, p. 789-804, 2008.

KIM, K. The Application of the Biosphere Reserve Concept to Urban Areas: the case of green rooftops for habitat network in Seoul. In: NEW YORK ACADEMY OF SCIENCES, 1023, 2004, New York. Proceedings... New York, 2004. p. 187214.

MEDIONDO, E. M.; CUNHA, A. R.

Experimento Hidrológico Para Aproveitamento de Águas de Chuva Usando Coberturas Verdes Leves. São Carlos, 2004. USP/SHS - Processo FAPESP 03/06580-7.

MORAN, A. A North Carolina Field Study to Evaluate Greenroof Runoff Quantity, Runoff Quality, and Plant Growth. Dissertation (M.S. Thesis) - North Carolina State University, Raleigh, North Carolina, 2004.

OLIVEIRA, E. W. N. Telhados Verdes Para Habitações de Interesse Social: retenção das águas pluviais e conforto térmico. Rio de Janeiro, 2009. 87 f. Dissertação (Mestrado em Engenharia Civil) - Faculdade de Engenharia, Universidade do Estado do Rio de Janeiro, Rio de Janeiro, 2009.
OHNUMA, A. A. Medidas Não Convencionais de Reservação d'Água e Controle de Poluição Hídrica em Lotes Domiciliares. São Carlos, 2008. 306 f. Tese (Doutorado em Ciências da Engenharia Ambiental) - Escola de Engenharia de São Carlos, Universidade de São Paulo, São Carlos, 2008.

PECK, S. W. et al. Greenbacks From Green Roofs: forging a new industry in Canada. Canada Mortgage and Housing Corporation. 1999. Disponível em: 〈http://www.greenroofs.org>. Acesso em: 15 mar. 2014.

PINTO, E. M. A. Gestão de Recursos Hídricos e as Interferências do Sistema Urbano: município de Queimados - RJ. Revista Universidade Rural, Série Ciências Humanas e Sociais, Rio de Janeiro, v. 29, n. 1, p. 125-131. jan./jun. 2007.

RENTERGHEM, V. T.; BOTTELDOOREN, D. Reducing the Acoustical Façade Load From Road Traffic With Green Roofs. Building and Environment, v. 44, n. 5, p. 1081-1087, may 2009.

ROCHA, L. M. V.; SOUZA, L. C. L.; CASTILHO, F. J. V. Ocupação do Solo e Ilha de Calor Noturna em Avenidas Marginais a Um Córrego Urbano. Ambiente Construído, Porto Alegre, v. 11, n. 3, p. 161-175, jul./set. 2011. ROSENZWEIG, C.; GAFFIN, S.; PARSHALL, L. Green Roofs in the New York Metropolitan Region: Research Report. Columbia: Columbia University Center for Climate Systems Research and NASA Goddard Institute for Space Studies, 2006. 60 p.

SANTOS, P. T. S. et al. Telhado Verde: desempenho do sistema construtivo na redução do escoamento superficial. Ambiente Construído, Porto Alegre, v. 13, n. 1, p. 161-174, jan./mar. 2013.

SILVA, D. T. Instalação e Avaliação de Um Telhado Verde em Relação à Utilização das Espécies Gazania Rigens e Kalanchoe Blossfeldiana em Santa Maria - RS. Santa Maria, 2010. 48 f. Monigrafia (Trabalho de Conclusão de Curso) - Curso de Engenharia Florestal, Universidade Federal de Santa Maria, Santa Maria, 2010.

TUCCI, C. E. M. Gestão de Inundações Urbanas. Ministérios das Cidades - Global Water Partnership - World Bank - Unesco. 269 p. 2005.

TUCCI, C. E. M.; BELTRAME, L. F. S.

Evaporação e Evapotranspiração. In: TUCCI, C. E. M. (Org.). Hidrologia: ciência e aplicação. Porto Alegre, Editora da Universidade, 1993. p. 253-288. 
UNITED NATIONS POPULATION FOUND.

The State of World Population. [S.1.]: United Nations Population Found, 2013. 140 p.

UNITED STATE ENVIRONMENTAL PROTECTION AGENCY. Protecting Water Quality From Urban Runoff. Washington, D.C.: U.S. Environmental Protection Agency, 2003.

UNITED STATE GREEN BUILDING

COUNCIL. An introduction to the U.S. Green Building Council and the LEED Green Building Rating System. 2005. Disponível em:

<http://www.usgbc.org/Docs/Resources/usgbc_intr o.pppt>. Acesso em: 15 mar. 2014.
URBONAS, S. B.; STAHRE, P. Stormwater Best Management Practices and Detention. New Jersey: Englewood Cliffs, 1993. 440 p.

VECCHIA, F. Cobertura Verde Leve (CVL): ensaio experimental. In: ENCONTRO NACIONAL DE CONFORTO NO AMBIENTE CONSTRUÍDO, 6., Maceió, 2005, Maceió. Anais... Maceió: ANTAC, 2005.

YANG, J.; YU, Q.; GONG, P. Quantifying Air Pollution Removal by Green Roofs in Chicago. Atmospheric Environment, v. 42, n. 31, p. 72667273, oct. 2008.

\section{Rutinéia Tassi}

Departamento de Egenharia Sanitária e Ambiental, Centro de Tecnologia | Universidade Federal de Santa Maria | Av. Roraima, 1000, Cidade Universitária, Camobi | Santa Maria - RS - Brasil | CEP 97105-900 | Te.: (55) 32208423 | E-mail: rutineia@gmail.com

\section{Lucas Camargo da Silva Tassinari}

Acadêmico do curso de Engenharia Civil, Centro de Tecnologia | Universidade Federal de Santa Maria | Email: lucascst@hotmail.com

Daniel Gustavo Allasia Piccilli

Departamento de Engenharia Sanitária e Ambiental, Centro de Tecnologia | Universidade Federal de Santa Maria |

Email: dallasia@gmail.com

\section{Cristiano Gabriel Persch}

Departamento de Engenharia Civil | Universidade Federal de Santa Maria | Email: cgpersch@gmail.com

Revista Ambiente Construído

Associação Nacional de Tecnologia do Ambiente Construído

Av. Osvaldo Aranha, $99-3^{\circ}$ andar, Centro

Porto Alegre - RS - Brasil CEP $90035-190$

Telefone: +55 (51) 3308-4084

Fax: +55 (51) 3308-4054

www.seer.ufrgs.br/ambienteconstruido

E-mail: ambienteconstruido@ufrgs.br 